\title{
Essays
}

\section{An overview of the proposal for a new Package Travel Directive}

\author{
Josep M. Bech Serrat ${ }^{*}$, Girona
}

\begin{abstract}
After an endless wait, a proposal for a new Package Travel Directive repealing Directive 90/314/EEC ${ }^{1}$ was presented on 9 July 2013 (hereafter, the Proposal). ${ }^{2}$ This article is aimed at providing an overall view of the Proposal. I will address the following issues: (i). The concept of traveller; (ii). online package holidays and assisted travel arrangements; (iii). information requirements; (iv). a new particular right of withdrawal for package travel; (v) other changes to the contract before the start of the package; (vi). performance of the Package; and (vii) insolvency protection. Some early concluding remarks are made as to when a future Package Travel Directive might take place at some future date (section VIII). ${ }^{3}$
\end{abstract}

\section{The 'traveller' in the proposal for a new PTD}

Persons protected by the proposal are referred to as 'travellers' and they are defined as any person who is seeking to conclude, or is entitled to travel on, the basis of a contract concluded within the scope of the Proposal. They are not defined as 'consumers' so as to protect representatives of small businesses and professionals who book trips related to their business or profession through the same booking channels as consumers (Recital 7).

The approach is in line with travel law conceived of as one field of EU law connected to providing a protection which is not limited to those consumers as defined in Art. 2 Para.1 of Consumer Rights Directive, namely natural persons who are acting for purposes outside their trade, business, craft or profession.

However, business travellers were included in the proposed definition 'insofar as they do not travel on the basis of a framework contract with a trader specializing in the arrangement of business travel' (Art. 3 point 6). It was deemed that those travel arrangements made by big companies or organizations for their employees on the basis of a framework contract with companies which specialize in the arrangement of business travel do not require protection (Recital 7).

\section{Online package holidays and assisted travel arrangements}

There has been a substantial trend towards buying travel services through the Internet since the current PTD entered into force. The traveller frequently prefers to book transport, ac- commodation, car rental and/ or other services in this way and design his own travel, eventually after having a look at online consumers' reviews. The phenomenon significantly differs from traditional travel packages which were regulated by the Directive, exclusively offered on the premises (face to face) and by means of brochures and mostly designed (whether with a pre-arranged combination or not) by the organiser. The new technologies have changed the contracting process itself in the last decades and a gap in the PTD has caused uncertainty to stakeholders and hurt competition to the detriment of off-line/ traditional traders. ${ }^{4}$ In the meantime, European member states have turned their back on the new ways of travelling though the opportunity offered by the PTD to regulate the issue so as to protect the consumers on the basis of a minimum harmonization principle. ${ }^{5}$ A proposal for a new regulation of online travel services was the biggest challenge to be faced by the European legislator and this cause a long delay in the drafting. Together with the complexity inherent to these services, huge economic interests, defended by lobbies, were involved.

* The author is Associate Professor in Civil Law at the University of Girona, Spain. E-Mail address: josepm.bech@udg.edu. This article is an updated version of a presentation at 24th IFTTA World Conference on Travel and Tourism Law which took place at Charles University, Prague, Czech Republic, in October 23-26, 2013. The author expresses his gratitude to both Prof. Dr. Klaus Tonner for giving encouragement to publish it and Mr. John Downes for the proofreading. Any mistake was solely made by the author.

1 Directive 90/314/EEC (hereafter, PTD).

2 COM (2013) 512. The European Commission published a working document on 26 July 2007, http://ec.europa.eu/consumers/ rights/commission_working_document_final26-07-2007.pdf accessed 3 February 2014.

3 At the time of writing the Proposal has been approved by 35 votes to 2 in the Committee on Internal Market and Consumer Protection (IMCO), 11 February of 2014, and the report is scheduled for a plenary vote in March when the European Parliament will conclude the first reading. As for the timing, see http://www.europarl.europa.eu/committees/en/imco/subjectfiles.html?id=20131112CDT74352\#menuzone accessed 12 February 2014.

4 'Consumer Detriment Study in the area of Dynamic Packages', http://ec.europa.eu/consumers/strategy/docs/study_consumer_ detriment.pdf accessed 10 September 2013.

5 Art. 8 of the PTD. 
Now the Proposal distinguishes between package holidays and assisted travel arrangements and assumes that both modalities can take place over the Internet. The online travel packages are covered by most of the provisions contained in the Proposal and they are formed by four key components (Art. 3 Para. 2 lit (b)(v)): 1) a combination of at least two different travel services for the purpose of the same trip or holiday; ${ }^{6}$ 2) the services must be purchased from separate traders through linked through online booking processes; 3 ) the traveller's name or particulars needed to conclude a booking transaction must be transferred between the traders at the latest when the booking of the first service is confirmed; and 4) the traveller must perceive that there is a person (natural or legal) responsible for the whole package, i. e. a subject is acting as an organiser. ${ }^{7}$ Therefore, some requirements will be the same as in traditional travel package - requirements 1) and 4) $-{ }^{8}$ meaning that it will be possible to take some evidential pointers into account when determining whether or not particular arrangements are an online package travel, such as whether the word 'package' was used or not in the information the traveller was provided with; whether the components were sold at a price different from the sum of the individual parts; or whether the traveller was informed by the online business that he could purchase any one or more of those services without any need to purchase the others. In some cases there will be little difficulty in concluding that the services were sold as a package by considering all these circumstances. ${ }^{9}$ Other requirements are more related to the particular features of the online contracting process itself. With regard to this, a preexisting linked online booking process between the separate traders beyond other technological aspects, e.g. whether the traveller is kept on the same Internet site or by way of linked Internet sites, seems to be appropriate - requirement 2 -.

Concerning the online assisted travel arrangements, the following requirements are provided in the Proposal (Art. 3 Para. 5, lit b): 1) a combination of at least two different types of travel services for the purpose of the same trip or holiday; 2) the traveller concludes separate contracts with the individual travel service providers; 3 ) the former combination must be facilitated by a retailer through the procurement of additional travel services from another trader in a targeted manner through a linked online booking processes at the latest when the booking of the first service is confirmed..$^{10}$ The latter requirement will be essential for the online travel services to be characterized: the operator merely helps the traveller to combine the travel services and, additionally, the help is to be given in a very particular way. Thus, online travel services will take place, for example, where, along with the confirmation of the booking of a first travel service such as a flight, a consumer receives an invitation to book an available hotel at the destination, with a link to the booking site of the hotel. Although it has been pointed out that the new definition of package (Art. 3 Para.2, particularly lit b (i) and (ii)) is so wide it does not leave much room for assisted travel arrangements at all, we forecast that they are going to be much more than only 'just fifteen minutes of fame.' ${ }^{11}$
As there is no subject acting as organiser and assuming the responsibility for the whole services, unlike the case with online package holidays, only a few provisions of the Proposal will be applicable. The most relevant rules will be those concerning insolvency protection (Arts. 15 and 16); those obliging to inform the traveller that every service provider will be the only person responsible for the performance; non-application of most of the traveller's rights provided in the Proposal (Art. 17); and that establishing a liability of the retailer for making booking errors (Art. 19). ${ }^{12}$

In addition, online assisted travel arrangements should be distinguished from those links through which travellers are simply informed about further travel services in a general fashion, for instance where a hotel or an organiser of an event includes on its website a list of all operators offering transport services to its location independently of any booking or if cookies or meta data are used to place advertisements on websites. $^{13}$

Consequently, the Proposal creates a legal framework for new ways of travelling by taking some features of the online contracting process into consideration. As far as we know there is no precedent like this regulation. We consider that it is too early to make an accurate assessment of the practical problems which can arise from the application of this regulation beyond some international private law issues, i. e. rules on applicable law and competent courts. In any case, the rules of Proposal are novel, do not include some technicalities related

6 All combinations are included, whether travel services are combined before any contact with the traveller or at the request of or according to the selection made by the traveller (Recital 8). This is in line with Judgment in ECJ 30.4.2002, C-400/00 - Club Tour. Cf. Art. 2, point 1 of the PTD.

7 Recitals 8 and 20 of the Proposal.

8 However, the choice of elements has increased from three to four, as car hire has been added as a distinct category of its own, so the old conundrum 'can Fly-Drive be a package?' is resoundingly answered 'yes'. S. Mason / M. Gatenby, "Proposals for a new Package Travel Directive: the definition of 'package' and 'assisted travel arrangement'”, TLQ 2013, p. 197. In addition, there is a suggestion in the preamble that other services should equate in value to at least $20 \%$ of the package price or otherwise represent an essential feature of the trip or holiday (Recital 17).

9 E.g. see the Guidance 'What is a Package?' published by the UK Government, Department for Business, Enterprise and Regulatory Reform.

10 In the consultation questionnaire of the new PTD the papers were silent on whether single travel components which are booked separately should be included within the scope of the Directive. Only the Bureau Européen des Unions des Consommateurs (BEUC) argued for inclusion of 'stand-alone-services'. See K. Tonner, 'Modernising package travel: towards a new Directive', IFTTA Law Review 2011, p. 3.

11 Cf. Mason / Gatenby (2013), n. 10 above, at p. 199-200, consider that agents can be classified as organisers in three easy steps when looking at the definitions of what is a package under Art. 3 Para. 2 of the Proposal and particularly the inclusion of 'total price' in lit. (b) (ii).

12 Art. 2 Para. 1 of the Proposal.

13 Recital 11 of the Proposal. 
to the use of new technologies which could be to the detriment to the clarity and make it clear that some consensus between the stakeholders, i.e. organisers, retailers, airlines, hotels and consumers, was achieved. ${ }^{14}$

\section{Information requirements}

As for information requirements some provisions of the current PTD, which were successful in achieving their objectives, were maintained in the Proposal. Thus a minimum of information very specific to the tourism industry is established (Art. 4 Para. 1) and the organiser and the retailer shall provide the traveller with information at different stages (Art. 4 to Art. 6). With regard to this, the most appropriate time for providing some information the traveller does not (yet) need is not necessarily prior to conclusion of the contract, e.g. information on visa requirements or transport connections. The traveller normally pays attention to other information before concluding the contract and changes are possible at the very last moment before the start of the package. Likewise, maintaining an exception to the binding character of the brochure on the organizer whereby possible changes in particulars contained in the brochure are expressly stated and clearly communicated to the consumer before concluding the contract (Art. 5 Para. 1) seems to be a good strategy for travel services.

In addition, some progress was made by the Proposal following the Consumer Rights Directive ${ }^{15}$ as a model. In that sense, if the information on additional charges, fees or other costs when informing of the total price of the package is not provided prior to conclusion of the contract, it is expressly stated that the traveller shall not bear them (Art. 5 Para.2); ${ }^{16}$ and a durable medium requirement for providing a copy of the contract or a confirmation of the contract at or immediately after its conclusion was introduced (Art. 5 Para. 3). ${ }^{17} \mathrm{~A}$ 'durable medium' means any instrument which enables the traveller or the operator to store information addressed personally to him in a way accessible for future reference for a period of time adequate for the purposes of the information and which allows the unchanged reproduction of the information stored (Art. 3 point 10), thus including USB sticks, CD-ROMs, DVDs, memory cards or the hard disks of computers, as well as electronic mail. Another advance is imposing an 'obligation to pay' button, that is to say, the trader shall ensure that when placing his order the traveller explicitly acknowledges that it implies an obligation to pay where a distance contract to be concluded by electronic means places the traveller under such an obligation (Art. 25 Para.2 of the Proposal with a reference to Art. 8 Para. 2 Sub-para. 2 of the Consumer Rights Directive).

Likewise, another improvement consisting of providing sufficient information to the traveller when the service is not realized, e.g. the service is 'cancelled' by the trader or a change in the package is made, is also to be applauded. In contrast to most information requirements at EU level which mainly focus on the pre-contractual stage, the Proposal establishes that ' $\mathrm{t}$ ] aking into account the specificities of package travel contracts, rights and obligations of the parties should be laid down, for the time before and after the start of the package, in particular if the package is not properly performed or if particular circumstances change' (Recital 25). Regarding this, it is quite common for some organizers, retailers, airlines, and hoteliers to only inform travellers about the availability of an alternative service but not about their right to be repaid as provided by travel law legislation. These traders take advantage of the regulatory gap by distorting the consumer's behavior when choosing between an alternative or termination. Although this could be regarded as an unfair commercial practice, we consider that additional rules on information should be introduced so as to guarantee the effectiveness of the consumer's rights. ${ }^{18}$

Nevertheless, some questions regarding information requirements still remain open. Thus, firstly, the Proposal does not seek to prevent the traveller being overloaded with information, i.e. information is to be provided even if it is already apparent from the context. ${ }^{19}$ Secondly, the extension of information to be provided to the traveller depending on the product or the medium used for concluding a distance contract remains unclear. ${ }^{20}$ Thirdly, essentially by removing references to brochures, the Commission has acknowledged that the provision of information can take many forms, including digital and online formats; and organizers and retailers were allowed to provide the traveller with 'key [pre-contractual] information on the organizer's website' (Recital 23) at a time when there is a plea by the travel industry to replace the obligation to provide traditional brochures but it is still not fully clear when an Internet site should be qualified as a durable medium in the EU consumer acquis. With regard to this, the Commission has stated that 'with the internet, there seems less need for specific printed information' and ' $t]$ he current rules have led businesses to unnecessarily reprint their advertising material, incurring undue costs of about $€ 390$ million per year'; yet - it is added by the Commission- 'the proposal

14 In the consultation questionnaire of the new PTD the Commission suggested the following possible wording to include dynamic packaging: '[p]ackages including accommodation, transport and / or other tourist services purchased on the internet from the same site where consumers can assemble the content of the package and packages including [...] purchased on the internet from different sites which are clearly linked on their web pages'. See Tonner (2011), n. 12 above, at p. 3.

15 Directive 2011/83/EU.

16 See also Art. 4 Para. 1, lit. (c) of the Proposal. This is in line with Art. 6 Para. 6 of the Consumer Rights Directive.

17 In contrast to this Art. 4 Para. 1 lit. (a) and (b) of the PTD establishes that the information is to be provided 'in writing or any other appropriate form, before the contract is concluded'.

18 See also Art. 9 Para. 2 of the Proposal. Cf. Art. 19 Para. 2 of Bus passengers' rights Reg (EU) 181/2011; Art. 14 of the proposal for a Reg amending the Air Passengers Rights Reg and Reg (EC) $2027 / 97$ on air carrier liability in respect of the carriage of passengers and their baggage by air, COM (2013) 130 final.

19 Cf. Art. 5 Para. 1 of the Consumer Rights Directive.

20 Cf. Recital 36 and Art. 6 Para. 1 lit. (a) of the Consumer Rights Directive. 
ensures that the traveller will still receive all the key information before signing a contract and that any potentially important news after that, for instance a change to the itinerary, is communicated in writing (including email)..${ }^{21}$ However, the Court of Justice of the European Union has decided that an 'ordinary' website cannot be regarded as a durable medium, although the decision did not exclude the possibility that there may be sophisticated websites that do meet the requirements of a durable medium; ${ }^{22}$ and our view is that an Internet site should be qualified as a durable medium only when, apart from enabling the consumer to store the information for as long as it is relevant for him to protect his interests stemming from his relationship with the operator, the information can be stored in such a way as to make it impossible for the trader to later invoke information changed unilaterally by him. ${ }^{23}$

\section{A new particular right of withdrawal for travel packages}

What is a very welcome novelty in the proposal for a new Package Travel Directive is a regulation of a particular right of withdrawal from travel packages (Art. 10 Para.1). As is commonly known, a right to withdraw allows the consumer to decide not to continue with the contract by communicating it to the trader within a time limit and without the need to give a reason. Such a right can be very relevant when selling travel services.

We have reason to regard this provision in the proposed regulation as most welcome. No formal requirement as to how traveller may withdraw from the contract was imposed, whereas a rigorous compliance with formal requirements would probably have contradicted the goal of the directive to protect consumers.

Another welcome point is that the withdrawal right was conceived as to be exercised before the start of the package. The traveller was not entitled to withdraw from the contract within a certain period of time, i. e. the consumer shall not have a period of 14 days to withdraw from the contract. ${ }^{24}$ Hence the Proposal is coherent with that function of a withdrawal right in travel packages aimed at addressing an impediment for the traveller which arises after booking and before the start of the package, $^{25}$ and a right to be exercised before the start of the package will promote booking in advance - as the more in advance the booking is made, the more time under protection- and avoids a problem which could arise from allowing the traveller to withdraw after beginning the performance of travel services, particularly in so-called last-minute bookings, making exercising of the right more complicated.

Beside this, compensation to the organizer, as provided in the Proposal, will be appropriate, calculated on a basis of reasonable standardised cancellations fees based on the time of cancellation and the customary cost savings and income from alternative deployment of the travel services as specified in the contract or, in the absence, corresponding to the price of the package minus the expenses saved by the organizer (Art. 10 Para. 1). In this sense, exercising the right of withdrawal has the effect that parties are not bound by the contract and the consumer is not compelled to pay for the services and compensation -or, so much the better, a penalty- closely related to the phenomenon of setting aside capacity, which the trader may find it difficult to do in the wake of a right of withdrawal, is to be preferred. Although the calculation of the penalty will be difficult, i. e. the problem will be how the expenses saved by the organizer are to be calculated and proved, travel services cannot be returned by the client -unlike a pair of trousers sold online- and hence such a compensation is needed. ${ }^{26}$

\section{Other changes to the contract before the start of the package}

The proposed new Directive broadly maintains the structure of the previous Directive as far as pre-departure changes are concerned (Arts. 7 to 10). Even so, besides a right of withdrawal, Chapter III of the Proposal clarified some points compared with the current PTD. On the one hand, the costs of transferring the contract to another traveller were limited to the actual cost borne by the organiser (Recital 26 and Art. 7 Para. 2, second sentence). ${ }^{27}$ On the other hand, the proposed regulation expressly states that the price alteration may be a consequence of tourist taxes (Art. 8 Para. 1 lit (b)) and the price increase shall not exceed $10 \%$ of the price of the package (Art. 8 Para.2) and be valid only if the organiser notifies the traveller of it with a justification and calculation in a durable medium at the latest 20 days prior to the start of the package (Art. 8 Para. 3). These are the substantial differences in com-

21 Para. 3 of the Communication from the Commission to the European Parliament, the Council, the European Economic and Social Committee and the Committee of the bringing the EU Package Travel Rules into the Digital Age of 9 July 2013, COM (2013) 513 final.

22 ECJ 5.7.2012, C-49/11 - Content Services.

23 J.M. Bech Serrat, Selling Tourism Services at a Distance (2012) p. 75-76.

24 Cf. Art. 9 Para. 1 of the Consumer Rights Directive concerning a right of withdrawal from a distance or off-premises contract.

25 The function of the withdrawal right in package holidays is not to allow the traveller to rethink his decision of participating in the package within a certain period of time.

26 On the contrary, other EU Directives establish that the consumer shall not incur any liability as a consequence of exercising the right of withdrawal with service contracts concluded at a distance or off-premises under the Consumer Rights Directive (Art. 14 Para. 5); and the consumer shall bear no cost for the performance of services where the trader has failed to provide information on the withdrawal right or the consumer has not expressly requested performance to begin during the withdrawal period (Art. 14 Para. 4 lit. (a) of the Consumer Rights Directive).

27 Recital 26 provides that '[i]n such situations, the organiser should be able to recover his expenses, for instance if a sub-contractor requires a fee for changing the name of the traveller or for cancelling a transport ticket and issuing a new one'. It has been pointed out that this is probably the position under the current law in any event. S. Prager, 'Proposals for a new package travel Directive: pre-departure changes', TLQ 2013, p. 214. 
parison with the current PTD, yet it has been suggested that they may be more apparent than real. ${ }^{28}$

Likewise, alteration of other contract terms are specifically referred to any of the main characteristics of the travel services as defined in point (a) of Article 4 or special requirements of the traveller which the organiser has accepted as referred to in point (a) of Art. 6 Para. 2 (Art. 9 Para.2). According to point (a) of Art. 4, the main characteristics of the travel services are the following: (i) the travel destination(s), itinerary and periods of stay, with dates; (ii) the means, characteristics and categories of transport, the points, dates and time of departure and return or, where the exact time is not yet determined, the approximate time of departure and return, the duration and places of intermediate stops and transport connections; (iii) the location, main features and tourist category of the accommodation; (iv) whether meals are provided and, if so, the meal plan; (v) visits, excursion(s) or other services included in the total price agreed for the package; (vi) the language(s) in which the activities will be carried out and (vii) whether access for persons with reduced mobility is guaranteed throughout the trip or holiday, so that the scope of what is considered 'significant' has been widened. ${ }^{29}$ In addition, the Proposal allows for repayment to the traveller of any sums owing on termination within the period of fourteen days (Art. 9 Para.4) and not simply 'as soon as possible'.

\section{Performance of the Package}

A number of points regarding the performance of the package were also clarified by Chapter IV of the Proposal. Art. 11 covers what happens when things go wrong after departure. Regarding this, firstly, the proposed rules expressly state that suitable alternative arrangements must be made where the return to the place of departure is not provided as agreed (Art. 11 Para. 3); secondly, the traveller is entitled to reject the alternative arrangements proposed by the organiser because they are not comparable to what was agreed in the contract (Art. 11 Para. 4); thirdly, transport back is required only if the package includes the carriage of passengers (Art. 11 Para. 4); fourthly, a maximum of EUR 100 per night and three nights per traveller is imposed when it is impossible to ensure the traveller's timely return because of unavoidable and extraordinary circumstances is established, with exceptions for persons with reduced mobility, pregnant women, unaccompanied children and persons in need of specific medical assistance (Art. 11 Paras. 5 and 6); ${ }^{30}$ and fifthly, the limits of organiser's obligation to provide assistance to the traveller in difficulty are established, namely consisting mainly in: (a) providing appropriate information on health services, local authorities and consular assistance, and (b) assisting the traveller in making distance communications and alternative travel arrangements. The organiser shall be able to charge a reasonable fee for such assistance if the situation is caused by the traveller's negligence or intent (Art. 14). ${ }^{31}$

The current PTD is the only legislation of the consumer acquis which regulates compensation for damages in a situa- tion $t$ where liability issues are significantly linked to national law. With regard to this, a more complete regulation was intended to be provided for in the Proposal. Thus, compensation for non-material damage was expressly stated (Art. 12 Para. 2) and contracting parties were allowed to limit compensation to be paid by the organiser as long as that limitation does not apply to personal injury and damage caused intentionally or with gross negligence and does not amount to less than three times the total price of the package (Art. 12 Para. 4). Besides, in accordance with the Proposal it will be compulsory for the EU member states to provide the same limitations of the liability of services providers as the international conventions covering travel services. ${ }^{32}$ All these proposed provisions make clarifications compared with the current PTD.

However the wording of Art. 5 PTD has led to different national approaches regarding a right to compensate for damages and the Proposal fails to provide a straight answer as to other important issues. In particular, Art. 11 (1) of the Proposal states that 'Member States shall ensure that the organiser is responsible for the performance of the travel services included in the contract [...][emphasis added]'. Does it mean that the organizer will be in the firing line when things do not go as planned? ${ }^{33}$ In our opinion, here a several liability between the organiser and retailer, i.e. where each company is liable to the traveller only for the part of the damage attributable to him, should have been established regarding the performance of all the obligations arising from the contract and not the execution of the services only. ${ }^{34}$ In this sense, we consider it unfortunate to establish that ' $[\mathrm{i}] \mathrm{n}$ relation to packages, retailers should be responsible together with the organiser for the provision of pre-contractual information'. ${ }^{35}$ This provision seems to impose joint liability on the organiser and retailer as far as pre-contractual information is concerned, i.e. where the whole damage suffered by the traveller is attribut-

28 For a comparison with UK regulations, ibid., p. 215.

29 It has been suggested that, currently, tour operators disavow any obligation to provide a consumer's special requirements, but this is likely to be more difficult under the provisions of the new proposals. Ibid., p. 215.

30 This was aligned with the new paragraph 4 added to Art. 9 of the Air Passengers' Rights Regulation 261/2004 by Art. 1 Para.9 lit. (b) of the proposal for a Reg amending the Air Passengers Rights Reg and Reg (EC) 2027/97 on air carrier liability in respect of the carriage of passengers and their baggage by air. See Recital 30, last sentence of the Proposal. A new regulation on the issue is coming after the events arising from the Icelandic volcanic ash cloud.

31 Recital 32 of the Proposal.

32 Recital 30, second sentence of the Proposal. Cf. Art. 5 Para. 2 Sub-para. 3 of the PTD.

33 The question has been answered in the affirmative. A. Padfield, 'Proposals for a new package travel Directive: performance of the package', TLQ 2013, p. 217.

34 Art. 5 Para. 1 of the PTD establishes that 'Member States shall take the necessary steps to ensure that the organizer and / or retailer party to the contract is liable to the consumer for the proper performance of the obligations arising from the contract'.

35 Recital 21 of the Proposal. 
able to them both, but from our point of view several liability could be established here as well. Although retailers should be liable for booking errors (Art. 19), why to establish a different distribution of liability between the organiser and retailer depending on the particular obligation the liability arises from?

Likewise, the basis of liability has also been differently interpreted by national courts. It is unclear whether the liability under the current Art. 5 of the PTD is based on fault or is a strict liability. Obviously strict liability for damage is more suitable for a person who carries on an abnormally dangerous activity where damage is characteristic of the risk presented by the activity and resulting from it; whereas fault has not been abandoned in national law and even is present in the wording of the defences of Art. 5 Para. 2, e.g. 'to an event which the organizer and / or retailer or the supplier of services, even with all due care, could not foresee or forestall'. Indeed, fault is very important in the provision of tourist services which commonly form part of a package holiday, e.g. a hotel's liability is clearly based on fault; and hotel's negligence is very often presumed by courts when a safety standard is infringed. ${ }^{36}$ Here, there are some divergences between EU member states not only as to the burden of proof regarding negligence but also as to the interpretation of a force majeure case, so there is a need for clarification of this point in the Proposal. ${ }^{37}$ Otherwise a lack of harmonisation will continue if the Proposal is approved with the current drafting.

It is evident that it is very difficult to incorporate identical rules on compensation for damages into the different national legal systems. Liability issues stated in a new PTD will not be applied in isolation but will operate within non-harmonised national legal regimes (e.g. general contract law, case law and general interpretation of the rules).

Indeed some obscurities will still remain regarding the remedies for non-performance. Beyond compensation for damages, firstly it is provided for in the Proposal that if any of the services are not performed in accordance with the contract, the organiser shall remedy the lack of conformity, unless this is disproportionate (Art. 11 Para. 2). No further explanation is given as to what this means. ${ }^{38}$ Is this a cure by the debtor of non-conforming performance ${ }^{39}$ If affirmative, why was it formulated as an organiser's obligation? The remedy is unclear and no equivalent is found in EU contract law. ${ }^{40}$ Secondly, in accordance with the proposed regulation the traveller shall not be entitled to price reduction if the organiser proves that the lack of conformity is: (i) attributable to the traveller; (ii) attributable to a third party; or (iii) due to unavoidable and extraordinary circumstances (Art. 12 Para. 3 lit.(a)). Nevertheless, why is exoneration related to price reduction and limit the scope of this remedy for non-performance in this way? A non-performance attributable to the debtor is not required for price reduction in an EU legal framework. $^{41}$ Thirdly, a traveller's duty to inform the organiser without undue delay of any lack of conformity is not only imposed but establish as an exemption from organiser's liability (Art. 12 Para. 3 lit.(b)) and the provision is far from being clear in some countries, e.g. United Kingdom or Spain. ${ }^{42}$
Here we detect a need for the Proposal to approach to the remedies for non-performance in the light of European contract law. Some approach to European definitions, principles and model rules is observed in a field where national contract law still plays an important role. Thus, for example, situations where there is a lack of and improper performance of the travel services included in a package are termed as a lack of conformity' with the contract in the Proposal (Art. 3 Para. 12, Art. 6 Para. 2 lit.(c), Art. 11 Para. 2, Art. 12 Para. 1 lit.(a), Paras. 2 and 3). ${ }^{43}$ Nevertheless, we still have a long way to go and some inventions in travel could be seem a bit frivolous when an impressive effort was already made so as to harmonise EU contract law, i.e. Principles of European Contract Law (hereafter, PECL) ${ }^{44}$ and DCFR. ${ }^{45}$ Although the Proposal is directed towards a specific field, we consider that it cannot walk alone.

36 F. Alleweldt / K. Tonner / M. McDonald / S. Kara / B. Ayata / U. Stenzel, 'Study on Safety and Liability Issues relating to Package Travel', Policy Department Economic and Scientific Policy, European Parliament (2008) p 33, http://www.europarl.europa.eu/ meetdocs/2004_2009/documents/dv/999/999000/999000en.pdf accessed 29 October 2013.

37 Compare Art. 5 Para. 2, Sub-para. 5 and Art. 4 Para. 6 Subpara. 2 of the PTD with Art. 3 point 11 and Art. 12 Para. 3 lit. (a) (iii) of the Proposal.

38 Padfield (2013), n. 42 above, at p. 217.

39 Art. 8:104 of the European Principles of Contract Law (hereafter, PECL) and Art. III.-3:201-205 of the Draft Common Frame of Reference (hereafter, DCFR).

40 The PTD currently states that '[i]n cases of complaint, the organizer and / or retailer or his local representative, if there is one, must make prompt efforts to find appropriate solutions' (Art. 6).

41 Compare with Art. 3 Para. 5 of Consumer Sales Directive (Directive 1999/44/EC), Art. 9:401 PECL and Art. III.-3:601 DCFR.

42 As for the controversy arising from Art. 12 Para. 3 lit. (b) of the Proposal in the light of the current UK regulations, Padfield (2013), n. 42 above, at p. 221.

43 Cf. Art. III.-3:107(1) and Art. III.-3:202(2) of the Draft of Common Frame of Reference (hereafter, DCFR). See also Art. 1 Para.2 lit.(f), Art. 2 Paras. 3 and 4, Art. 3 Paras. 1, 2, 3 and 6, Art. 4, Art. 5 Paras. 1, 2 and 3 and Art. 7 Para. 1 of the Consumer Sales Directive. However the issue of 'lack of conformity' of Art. 12 of the Proposal was pointed out as a question to be clarified: Padfield (2013), n. 42 above, at p. 222.

44 The text was prepared by the Commission on European Contract Law (Lando Commission): O. Lando\&aAslash;H. Beale (eds), Principles of European contract law (Parts. I and II) (2000).

45 The text was prepared by the Study Group on a European Civil Code and the Research Group on EC Private Law (Acquis Group). After the Communication on European Contract Law of 2001, COM (2001) 398 final, which provided the idea of inspiring and supporting academic works in order to help the Community legislator to achieve more coherent EC legislation, the Action Plan 2003 (COM (2003) 68 final) expressly introduced the idea of a Common Frame of Reference (CFR) as a political endeavour. As a starting point, a "Network of Excellence" was entrusted with the elaboration of a DCFR, of which parts were published in an Outline Edition at the beginning of 2009: C. von Bar / E. Clive (eds), Principles, definitions and models rules of European private law: Draft common frame of reference. 


\section{Insolvency protection}

Recital 34 of the Preamble provides that 'Member States should ensure that travellers purchasing a package or an assisted travel arrangement are fully protected against the insolvency of the organiser, of the retailer having facilitated the assisted travel arrangement or of any of the service providers'. This preamble principle appears to have been enacted in Art. 15 Para. 1, which requires member member states to require 'organisers and retailers facilitating the procurement of assisted travel arrangements' to have refund and repatriation arrangements in place in the event of insolvency. Under the current Directive an organiser, as a principal, not only has to provide against its own insolvency, but must take the risk of its suppliers, e.g. hotels or airlines, becoming insolvent. The difference however between the new proposals and the PTD is the creation of 'assisted travel arrangements' for which retailers are liable - but only 'in the event of insolvency' (Art. 17).

A more complete regulation on insolvency protection is provided for in the Proposal (Chapter V). Thus, the insolvency protection shall take into account the actual financial risk of the relevant trader's activities (Recital 34 and Art. 15 Para. 2), meaning that a limitation of liability is permitted in accordance with the actual financial risk. On the other hand, the Commission has recognised the growing trend for travel businesses to base themselves within other member States and, therefore, it is provided that each Member State must recognise the others' financial protection schemes and provide very clear support and answers to concerns raised about the operation of that scheme. The free movement of services shall be facilitated (Recital 35) and a mutual recognition of insolvency protection between EU member states (Art. 16 Para. 2). To facilitate the administrative cooperation and supervision of businesses which are active in different Member States with regard to insolvency protection, member states should be obliged to designate central contact points (Art. 16 Para. 2). ${ }^{46}$

According to the opinion of member states expressed during the consultation process of the new PTD, the existing insolvency systems work satisfactorily ${ }^{47}$ However, we consider that there are still important open questions regarding the insolvency protection as provided in the Proposal: firstly, is the refund of double payments of travellers to service providers guaranteed under the Proposal?; secondly, what about the issue of enforcement of the insolvency protection schemes?: ${ }^{48}$ and finally, it is unclear whether the solvency of travel businesses is to be secured before the start of its activity, i. e. no compulsory licensing was required by the Proposal. Maybe these questions should be addressed in a definite version.

\section{Early conclusions}

At this stage, any useful comment is necessarily limited since much will depend upon how the Proposal is altered over the coming months. Overall, the new provisions do not seem radically different from those that we have got used to working on over the past twenty years.

Important advances were introduced by the Proposal depending on the particular issue in the light of the Consumer Rights Directive. The field of package holidays was updated from a consumer law perspective. However some gaps were detected, particularly with regard to information requirements and a new particular right of withdrawal for travel packages.

In addition, some issues on performance of the travel package as provided in the proposal were also clarified and improved. However other issues on some remedies for nonperformance, i.e. compensation for damages, price reduction, a 'cure by debtor' and other issues, i. e. a duty to inform of any lack of conformity, are far from being in line with the European contract law. Although it is not predictable whether the ongoing discussion on a European contract law may influence the forthcoming Directive, ${ }^{49}$ here the PECL and model rules of the DCFR regarding remedies for non-performance should have a role in the current revision. Otherwise, when introduced, the Directive will no doubt keep litigators occupied for some time yet.

46 Does it create a 'back-door' pan-European financial protection scheme advocated by the consumer lobby? See F. Brehany, 'Proposals for a new package travel Directive: the insolvency provisions', TLQ 2013, p. 228-229.

47 As for the stakeholders' opinions, Tonner (2011), n. 12 above, at p. 3.

48 In ECJ 15.6.1999, C-140/97 - Rechberger the insurance was based on $5 \%$ of turnover over three months and the Member State was refused the defence that the losses only happened because they were unexpected and that there was poor trading. Regarding a critical view on low-level monitoring of travel companies or those who ran them, Brehany (2013), n. 54 above, at p. 228-229.

49 Tonner (2011), n. 12 above, at p. 4.

\section{Legal Notice: IFTTA Law Review}

Edited by the International Forum of Travel and Tourism Advocates

Editorial Board Klaus Tonner (responsible according to the press law), Stephanstr. 4, 18055 Rostock (Germany), Doug Crozier (Toronto), Stephan Keiler (Salzburg), Marc McDonald (Dublin)

IFTTA Law Review is published three times a year (April, August, December) as a supplement to the journal $\mathrm{RRa}$ - ReiseRecht aktuell.

Typesetting fidus Publikations-Service, Nördlingen

Printing Friedrich Pustet KG, Regensburg

Publisher sellier european law publishers $\mathrm{GmbH}$, Munich

(C) sellier european law publishers 2014

All rights reserved; no part of this publication may be reproduced, stored in a retrieval system, or transmitted in any form or by any means, electronic, mechanical, photocopying, recording or otherwise without prior written permission of the Publishers.

Quotation IFTTA L Rev, in RRa ISSN 2192-8592 